\title{
AN EXTENDED HARDY-HILBERT'S INEQUALITY WITH PARAMETERS AND APPLICATIONS
}

\author{
ZHAOHUI GU AND BICHENG YANG*
}

\begin{abstract}
By using the weight coefficients, the Euler-Maclaurin summation formula and Abel's summation by parts formula, an extended Hardy-Hilbert's inequality with the power function as the interval variables and a new Hilbert-type inequality with the partial sums are given. As applications, the equivalent conditions of the best possible constant factor in a particular inequality related to a few parameters and some particular cases are considered.
\end{abstract}

Mathematics subject classification (2020): 26D15.

Keywords and phrases: Weight coefficient, Euler-Maclaurin summation formula, Hardy-Hilbert's inequality, internal variable, parameter, partial sum.

\section{REFERENCES}

[1] G. H. Hardy, J. E. Littlewood and G. Polya, Inequalities, Cambridge University Press, Cambridge, 1934.

[2] M. KRniĆ And J. PeČArIĆ, Extension of Hilbert’s inequality, J. Math. Anal., Appl. 324 (1), 150-160 (2006).

[3] B. YANG, On a generalization of Hilbert double series theorem, J. Nanjing Univ. Math. Biquarterly, $18(1), 145-152,2001$.

[4] V. Adiyasuren, T. BATBold, L. E. AzAr, A new discrete Hilbert-type inequality involving partial sums, Journal of Inequalities and Applications, 2019:127, 2019.

[5] B. C. YANG, The norm of operator and Hilbert-type inequalities, Science Press, Beijing, China, 2009.

[6] M. Krnić And J. PeČARIć, General Hilbert's and Hardy's inequalities, Mathematical inequalities \& applications, 8 (1), 29-51 (2005).

[7] I. PERIĆ AND P. VUKović, Multiple Hilbert's type inequalities with a homogeneous kernel, Banach Journal of Mathematical Analysis, 5 (2), 33-43 (2011).

[8] Q. L. HuAng, A new extension of Hardy-Hilbert-type inequality, Journal of Inequalities and Applications (2015), 2015:397.

[9] B. HE, A multiple Hilbert-type discrete inequality with a new kernel and best possible constant factor, Journal of Mathematical Analysis and Applications, 431, 990-902 (2015).

[10] J. S. XU, Hardy-Hilbert's inequalities with two parameters, Advances in Mathematics, 36 (2), 63-76 (2007).

[11] Z. T. XIE, Z. ZENG AND Y. F. SUn, A new Hilbert-type inequality with the homogeneous kernel of degree -2, Advances and Applications in Mathematical Sciences, 12 (7), 391-401 (2013).

[12] Z. Zhen, K. Raja Rama Gandhi AND Z. T. XIE, A new Hilbert-type inequality with the homogeneous kernel of degree -2 and with the integral, Bulletin of Mathematical Sciences and Applications, 3 (1), 11-20 (2014).

[13] D. M. XIN, A Hilbert-type integral inequality with the homogeneous kernel of zero degree, Mathematical Theory and Applications, 30 (2), 70-74 (2010).

[14] L. E. AzAR, The connection between Hilbert and Hardy inequalities, Journal of Inequalities and Applications, 2013:452, 2013.

[15] V. AdiyASUREN, T. BATBOLD AND M. KRnić, Hilbert-type inequalities involving differential operators, the best constants and applications, Math. Inequal. Appl., 18, 111-124 (2015). 
[16] M. TH. Rassias, And B. C. YAng, On half-discrete Hilbert's inequality, Applied Mathematics and Computation, 220, 75-93 (2013).

[17] B. C. YANG AND M. KRnić, A half-discrete Hilbert-type inequality with a general homogeneous kernel of degree 0, Journal of Mathematical Inequalities, 6 (3), 401-417 (2012).

[18] M. TH. RASSIAS AND B. C. YANG, A multidimensional half-discrete Hilbert-type inequality and the Riemann zeta function, Applied Mathematics and Computation, 225, 263-277 (2013).

[19] M. TH. RASSIAS AND B. C. YANG, On a multidimensional half-discrete Hilbert-type inequality related to the hyperbolic cotangent function, Applied Mathematics and Computation, 242, 800-813 (2013).

[20] B. C. YAng And L. Debnath, Half-discrete Hilbert-type inequalities, World Scientific Publishing, Singapore, 2014.

[21] Y. HONG AND Y. WEN, A necessary and sufficient condition of that Hilbert type series inequality with homogeneous kernel has the best constant factor, Annals Mathematica, 37A (3), 329-336 (2016).

[22] Y. Hong, On the structure character of Hilbert's type integral inequality with homogeneous kernel and application, Journal of Jilin University (Science Edition), 55 (2), 189-194 (2017).

[23] Y. Hong, Q. L. HuAng, B. C. YAng AND J. L. LiaO, The necessary and sufficient conditions for the existence of a kind of Hilbert-type multiple integral inequality with the non-homogeneous kernel and its applications, Journal of Inequalities and Applications (2017), 2017:316.

[24] D. M. XIN, B. C. YANG AND A. Z. WANG, Equivalent property of a Hilbert-type integral inequality related to the beta function in the whole plane, Journal of Function Spaces, Volume 2018, Article ID2691816, 8 pages.

[25] Y. Hong, B. HE AND B. C. YANG, Necessary and sufficient conditions for the validity of Hilbert type integral inequalities with a class of quasi-homogeneous kernels and its application in operator theory, Journal of Mathematics Inequalities, 12 (3), 777-788 (2018).

[26] Z. X. HUANG AND B. C. YANG, Equivalent property of a half-discrete Hilbert's inequality with parameters, Journal of Inequalities and Applications (2018) 2018:333.

[27] B. C. YANG, S. H. Wu AND A. Z. WANG, On a reverse half-discrete Hardy-Hilbert's inequality with parameters, Mathematics, 2019, 7, 1054.

[28] A. Z. WANG, B. C. YANG AND Q. CHEN, Equivalent properties of a reverse's half-discret Hilbert's inequality, Journal of Inequalities and Applications (2019), 2019:279.

[29] X. S. HuAng, R. C. LuO And B. C. YAng, On a new extended Half-discrete Hilbert's inequality involving partial sums, Journal of Inequalities and Applications (2020) 2020:16.

[30] B. C. YAng, S. H. Wu AND Q. CHEN, On an extended Hardy-Littlewood-Polyá's inequality, AIMS Mathematics, 5 (2), 1550-1561 (2020).

[31] J. Q. LIAO, S. H. WU AND B. C. YANG, On a new half-discrete Hilbert-type inequality involving the variable upper limit integral and the partial sum, Mathematics, 2020, 8, 229; doi:10.3390/math8020229.

[32] B. C. YANG, M. F. HuAng AND Y. R. ZHONG, Equivalent statements of a more accurate extended Mulholland's inequality with a best possible constant factor, Mathematical Inequalities and Applications, 23 (1), 231-244 (2020).

[33] B. C. YANG, S. H. Wu AND A. Z. WANG, A new Hilbert-type inequality with positive homogeneous kernel and its equivalent form, Symmetric, 2020, 12, 342, doi:10.3390/sym12030342.

[34] Z. X. HuAng, Y. P. SHI AND B. C. YANG, On a reverse extended Hardy-Hilbert's Inequality, Journal of Inequalities and Applications (2020), 2020:68.

[35] M. Th. Rassias, B.C. YANG AND A. RAigorods KiI, On Hardy-type integral inequality in the whole plane related to the extended Hurwitz-zeta fanction, Journal of Inequalities and Applications (2020), 2020:94.

[36] J. Q. LiAO, Y. Hong AND B. C. YANG, Equivalent conditions of a Hilbert-type multiple integral inequality holding, Journal of Function Spaces, Volume 2020, Article ID 3050952, 6 pages.

[37] A. Z. WANG AND B. C. YANG, Equivalent property of a more accurate half-discrete Hilbert's inequality, Journal of Applied Analysis and Computation, 10 (3), 920-934 (2020).

[38] Y. Hong, J. Q. LiAO, B. C. YANG And Q. CHEN, A class of Hilbert-type multiple integral inequalities with the kernel of generalized homogeneous function and its applications, Journal of Inequalities and Applications (2020), 2020:140.

[39] B. C. YANG, S. H. WU AND Q. CHEN, A new extension of Hardy-Hilbert's inequality containing kernel of double power functions, Mathematics, 2020, 8, 339; doi:10.3390/math8060894. 
[40] J. C. KuAng, Applied inequalities, Shangdong Science and Technology Press, Jinan, China, 2004. 